\title{
Educational Needs and Care of Children with FASD
}

\author{
Molly N. Millians ${ }^{1}$
}

Published online: 23 June 2015

(C) Springer International Publishing Switzerland 2015

\begin{abstract}
The effects from prenatal alcohol exposure (PAE) can cause a range of neurobehavioral deficits that impact learning and functioning in school. As a result, children affected by PAE have diverse learning needs and may experience problems in school. Educational planning needs to be developed in accordance with the children's individual cognitive and learning profiles. Interventions need to focus on habilitation of the underlying deficits that influence learning within the context of an academic or school skill. Caregivers require information on how to advocate for their children's needs. Additionally, families, school personnel, and other professionals require training on the impact of PAE on development, learning, and school functioning. Using a comprehensive and collaborative approach to provide the necessary educational care for children with fetal alcohol spectrum disorders (FASD) may lessen the risk of academic and school failure.
\end{abstract}

Keywords Academics $\cdot$ FASD $\cdot$ Education $\cdot$ Interventions · Prenatal exposure to alcohol $\cdot$ School functioning

\section{Introduction}

Prenatal alcohol exposure (PAE) is a preventable cause of physical anomalies and a range of neurodevelopmental delays

This article is part of the Topical Collection on Fetal Alcohol Syndrome

Molly N. Millians

molly.n.millians@emory.edu

1 Department of Psychiatry and Behavioral Science, Emory University School of Medicine, 12 Executive Park South East, Suite 200, Atlanta, GA 30329, USA
$[1,2 \bullet, 3-5]$. Fetal alcohol spectrum disorders (FASD) is a nonclinical term used to describe the continuum of effects attributed to PAE. FASD includes the medical diagnoses of fetal alcohol syndrome (FAS) and partial fetal alcohol syndrome (pFAS) [1]. The severity of physical and cognitive effects caused by PAE varies among individuals $[1,2 \bullet \bullet, 3$, 4]. Many children affected by PAE exhibit global cognitive delays [5]. However, some children exhibit specific cognitive deficits in areas of working memory, executive functioning, visuospatial processing, and attention $[1,2 \bullet \bullet, 3-6]$. In addition, some children affected by PAE have experienced early deprivation, neglect, abuse, and multiple foster care placements caused by parental substance abuse, mental health problems, and social problems [7-9]. The combination of effects from PAE, negative environmental factors, and other possible co-occurring medical complications have a detrimental impact on children's learning, behavior, and school functioning [8,9]. As a result, many children affected by PAE are at risk for academic problems and school failure, especially if they do not receive appropriate supports and interventions [5, 8, 9]. The purpose for this paper is to examine the impact of PAE on children's academics and school functioning and then to present a collaborative approach to address the range of educational needs.

\section{FASD and School Functioning}

Studies using individually administered standardized measures of academic achievement, school-wide criterion-referenced tests, and teacher rating scales have shown many children affected by PAE exhibit problems in school [6, 7, 10-14]. Academic problems, notably in mathematics, have been identified, across age groups in children affected by PAE [10-14]. Some children and adolescents with PAE referred for clinical 
services reported having disrupted school experiences, defined as being suspended, expelled, or dropping out of school $[6,7]$. Streissguth, Bookstein, Barr, et al. [7] investigated adverse life events including disrupted school experiences, reported by patients with PAE referred for clinical services. The authors indicated that $14 \%$ of the children between 6 and 11 years of age and $61 \%$ of the adolescents between 12 and 20 years of age reported having disrupted school experiences. Forty-two percent of the participants reported receiving special education services. A more recent study conducted in Sweden examined the outcomes of adults with PAE [15•]. The authors indicated that $25 \%$ of the adults affected by PAE attended special education programs in primary school $[15 \bullet]$. Regardless of attending special education programs, the adults affected by PAE in the study completed at the least a secondary school education [15•]. The authors indicted that educational supports are provided to students regardless of attending special education programs $[6,7,15 \cdot]$. These studies highlight the risks and the need for special education and supportive services throughout formal education for children affected by PAE.

\section{FASD and School Experiences}

Qualitative studies examining the experiences of caregivers, teachers, and students affected by PAE illustrate the challenges and successes to obtain services and prevent school failure [16, 17, 18•, 19-23]. Caregivers reported having high levels of stress obtaining evaluations, services, and educational support for their children with PAE. Biological mothers reported feelings of self-blame and being judged by family members and school personnel when their children with PAE exhibited problems at school [16]. Biological mothers and other caregivers reported feeling shunned and isolated due to the lack of awareness of PAE by many teachers and school personnel [16]. The stigma associated with PAE may keep some caregivers from disclosing important information needed to obtain an accurate diagnosis and appropriate services.

Caregivers expressed concerns about limited access to resources for children with PAE. Caregivers reported difficulties locating evaluators trained to discern the effects from PAE from other developmental disorders in order to guide effective treatment planning [16, 17, 23]. Caregivers who obtained services felt they were insufficient to address the needs of their children with PAE [17]. They indicated that many teachers and school personnel had limited knowledge of strategies to support alcohol-affected children in the classroom [16, 17, 18•]. Caregivers indicated they were required to have frequent communication with teachers to monitor their children's progress. Some caregivers reported feeling frustrated having to educate teachers and school personnel about the effects of
PAE on learning each year as their children progressed through the grade levels [17].

Teachers expressed frustration with medical and clinical providers who work with children affected by PAE [17, 21] Teachers reported that evaluations were difficult to understand because they were written in medical or technical terminology $[17,21,22]$. Teachers indicated that often diagnostic reports and recommendations did not provide specific information on how to address the learning problems associated with the effects from PAE in a classroom setting. Many teachers indicated they were unaware of having students with a diagnosis of FAS or pFAS in their classes [17]. This may be due to caregivers' hesitation to share the information for fear of their children being shunned or due to limited communication between education specialists and classroom instructors [16].

Teachers reported differences in their abilities to differentiate instruction to address the learning and behavior challenges of children with PAE in the classroom [17, 19, 20]. Novice teachers were described as having more frustration with children affected by PAE in their classes than more experienced teachers [17]. More experienced teachers reported being able to modify instruction and classroom demands. Some teachers had received in-service training on the effects of PAE. However, many of the teachers indicated that the training focused on the medical diagnosis of FAS and was not relevant to a classroom setting [16, 17, 19, 20]. Educators would benefit from training programs that provided strategies on ways to support alcoholaffected children within a classroom and school setting.

High school students affected by PAE were interviewed in several of the studies $[17,19,20]$. All of the students interviewed were receiving high school instruction in special education classes $[17,20]$. Most of the students had been placed in the general education setting when they entered elementary school $[17,19,20]$. They transitioned to special education classes as they struggled to meet the academic demands as they progressed into higher grade levels. Some students were placed in special programs due to behavior problems at school. None of the students were reported to be performing on grade level, and academic instruction had been modified. However, all of the students were reported as motivated and were planning to complete high school [20]. The students were described as having caregivers who were involved and able to advocate for their children's needs [20].

These studies described the challenges experienced by caregivers seeking services in schools and in the community for children with FASD. These studies draw attention to the need for inclusive and collaborative programs to ensure access to supports and services.

\section{FASD and Academic Skills}

Learning requires the interactions of multiple cognitive processes including controlled attention, executive functioning, 
and memory [24]. Impairments in one or more cognitive processes due to PAE interfere with academic performance, especially in mathematics $[25 \bullet \cdot, 26]$. Coles, Brown, Smith, et al. [27] found that children 5 years of age affected by PAE showed deficiencies in sequential memory, early reading, and number skills. Other studies have identified relationships between timing, amount of intrauterine exposure, and lower scores on measures of arithmetic and word attack skills [10, 11]. Goldschmidt, Richardson, Stoffer, et al. [12] found heavy prenatal alcohol exposure during the second trimester of pregnancy and a threshold effect of one drink per day during the third trimester were related to lower scores on tests of word reading and spelling. The findings from a 10-year followup study suggested that second trimester binge drinking predicted lower scores on a measure of reading comprehension [13]. Recently, a study conducted in Australia found that children whose mothers drank heavily during the first trimester were twice as likely not to meet academic standards in reading on a nationally administered, criterion-referenced test of academic achievement [14]. The study indicated that maternal binge drinking, defined as five or more drinks in one setting, was associated with failing to meet the academic standards in writing. Though the authors did not discuss controlling for factors that might influence academic performance, the findings were consistent with clinical studies showing the effects of PAE on academic skills [10-14].

Relative deficits in mathematics have been associated with the effects from PAE across studies [10, 25••, 26]. Howell, Lynch, Platzman, et al. [26] reported alcohol-affected adolescents had significantly lower scores on tests of mathematical achievement as compared to adolescents who were prenatally exposed but not affected and to a special education contrast group. Impairments with basic numerical processes, including estimating and determining number magnitude, are associated with the effects from PAE [28-30]. Children with PAE who exhibit deficits with basic numerical processes, weaknesses with visuospatial processes, and poor attentional control may experience problems with arithmetic [30,31]. Children with poor attentional control and visuospatial weaknesses may overlook changes in operational signs when completing a worksheet, misalign numbers when writing equations, and have difficulties mentally representing information to solve problems $[24,25 \bullet \bullet, 32]$.

\section{FASD and Language and Social Skill Deficits}

Problems with language, communication, and social interactions interfere with functioning in a classroom setting. Studies have shown that children with PAE have deficits encoding verbal information [33-37]. Children with weaknesses encoding language may display problems following multistep directions or classroom discussions. However, when using specific strategies, children with PAE are able to encode and retain verbal information $[35,37]$.

Children affected by PAE exhibit problems with planning and organizing steps to complete tasks [38]. Difficulties with planning and organizing are noted in their use of language to retell a story or talk about an event $[38,39]$. Often children affected by PAE have problems selecting and organizing relevant information to express ideas in a logical sequence [38]. Difficulties with expressing ideas in a cohesive manner would impact children's participation in class discussion and interactions with teachers and peers [38-40].

Additionally, children with PAE are reported to have difficulties analyzing complex social situations and understanding different perspectives $[41,42 \bullet \bullet$. This may lead to misunderstandings between classmates and problems negotiating peer conflict. Children with PAE are reported to initiate and engage in social interactions $[39,40,43]$. However, they are noted to exhibit variability sustaining interactions in classroom settings [43]. The reported unpredictability of interactions may increase avoidance by peers and teachers' reports of behavior problems.

\section{FASD and Problematic Behavior}

Teachers and caregivers of children affected by PAE frequently report concerns about behavior at school. Consistently, across studies, teachers have rated children affected by PAE as having difficulties paying attention and following directions $[6,7,44]$. Streissguth, Bookstein, Barr, et al. [7] found that $70 \%$ of children and youth with PAE between the ages of 6 and 20 years, referred for clinical services, reported problems with attention and $58 \%$ noted problems completing school work. Also, $58 \%$ of patients with PAE reported problems with peer interactions and $55 \%$ reported displaying disruptive behaviors in the classroom. Other studies have indicated problems with persistence and calming after high-level activities in school associated with the effects from PAE [7, 44].

In contrast, some studies examining academic and school functioning of adolescents with PAE recruited from prospective longitudinal studies reported no differences in problematic behaviors when compared to nonexposed adolescents [26, 45] who were matched on social demographic characteristics. The study found that higher levels of adverse life events, such as poverty, and caregiver substance abuse were associated with increases in adolescents' delinquent behaviors. Using the same prospective cohort, Howell, Lynch, Platzman, et al. [26] examined school conduct reports of adolescents prenatally exposed to alcohol, nonexposed adolescents, and adolescents who received special education services. The findings showed no increase in reported conduct problems in adolescents prenatally exposed to alcohol when compared to the nonexposed adolescents and to adolescents receiving special education. Most likely, the differences in the findings from this prospective longitudinal sample were due to 
dissimilarities between the samples recruited from populations referred for clinical services and those recruited from the community. The findings illustrate the need to examine social and environmental factors that may influence behavior of children affected by PAE in order to develop effective school interventions $[26,45,46]$.

Not all children affected by PAE have experienced environmental neglect or adverse life situations and yet still display problematic behaviors at school. Their behaviors may be directly associated with brain damage caused by PAE [47-49]. Some children affected by PAE exhibit problems with controlled attention, inhibition, and cognitive flexibility [1, 2••, $3-5,49]$. These executive processes influence self-regulation or the ability to modulate emotions, behavior, and arousal level across settings [50]. Difficulties with self-regulation impact learning readiness, the skills to maintain consistent effort to complete school tasks, and the ability to calm and transition to paper-and-pencil tasks after high-level activities [51]. Many children affected by PAE are reported to display behaviors that are described as impulsive, inattentive, and off-task in a classroom setting [44]. There are strategies that may be used in a classroom to improve these behaviors. For example, directing children to use self-talk and methods to improve planning, awareness and engagement to the activity, as well reflecting upon the completion of the task have been shown to improve children's self-regulation and learning [52].

Behaviors associated with the effects of PAE appear similar to behaviors observed in children with attention deficit hyperactivity disorder (ADHD) [53-56]. However, there are differences between the two disorders $[55,56]$. Many children affected by PAE exhibit inefficient speed of processing, problems shifting attention, and difficulties modulating arousal level when both under- and overstimulated [56]. Children with ADHD are found to have problems with initiating and sustaining attention, maintaining internal motivation to complete tasks, and modulating arousal levels when under-stimulated $[1,2 \bullet \bullet$, $55,56]$. Also, studies have shown that children with ADHD exhibit more externalizing behavior problems when compared to children affected by PAE $[55,56]$. Distinguishing problems directly associated with PAE from ADHD may help with selecting the appropriate interventions to address problematic behaviors and improve functioning in a classroom setting.

\section{FASD, Educational Needs, and Recommended Interventions}

The Winnipeg School Division in Canada developed a collaborative educational program for children with FASD [57]. The program provided an inclusive educational setting that welcomed caregivers and children to ensure a positive school experience. Instructional programs were developed according to the children's cognitive and learning profile and addressed academic, social, and behavioral needs. Teachers and school personnel were provided training on the impact of PAE on learning. Though information about program efficacy was not provided, the program does provide a starting point when considering strategies to address the educational needs of alcohol-affected children. Based upon the description of the Winnipeg School Division's program and research on interventions for children affected by PAE, educational care requires collaboration between caregivers, medical and mental health providers, and school personnel to provide the necessary level of care [52, 57-59]. Figure 1 provides an overview of the factors that need to be considered when developing an educational plan for children with PAE.

\section{Evaluation, Diagnosis, and Learning Profiles}

Educational planning begins with a comprehensive developmental evaluation conducted by an interdisciplinary team trained to distinguish the effects of PAE from other developmental disorders $[16,18 \bullet, 21-23]$. The evaluation needs to assess cognitive abilities, social-emotional status, adaptive behavior, and academic achievement giving an outline of the children's cognitive and learning profile. The report from the evaluation needs to provide explicit recommendations that may be applied in an educational setting. The recommendations need to address any identified weaknesses as well as provide strategies to continue to support children's areas of strength and interests $[21,22]$. It is important for the evaluations to be useful to educators and other service providers.

\section{School and Class Placement}

Children affected by PAE show a continuum of impairments that impact learning. The selection of the type of school placement needs to be based upon the severity of the neurodevelopmental delays [60-62]. Due to low cognitive abilities or behavior problems, some children may require placement at a specialized program or in a small group setting at school in order to receive the necessary supervision, direct instruction, and interventions. Some children with PAE do well in classes taught by both a special education teacher and a general education teacher. Additionally, some children with PAE do well in a general education class with tutoring to support learning. School and class placement should depend upon the children's level of functioning and need for interventions $[57,60]$.

\section{Classroom Interventions}

Interventions in the classroom need to help children affected by PAE learn to cope with the academic, behavior, and social demands of the setting [59, 60]. Academic instruction needs to be scaffolded carefully, building upon prior skills [62]. Pacing of instruction needs to match the children's rate of processing with 


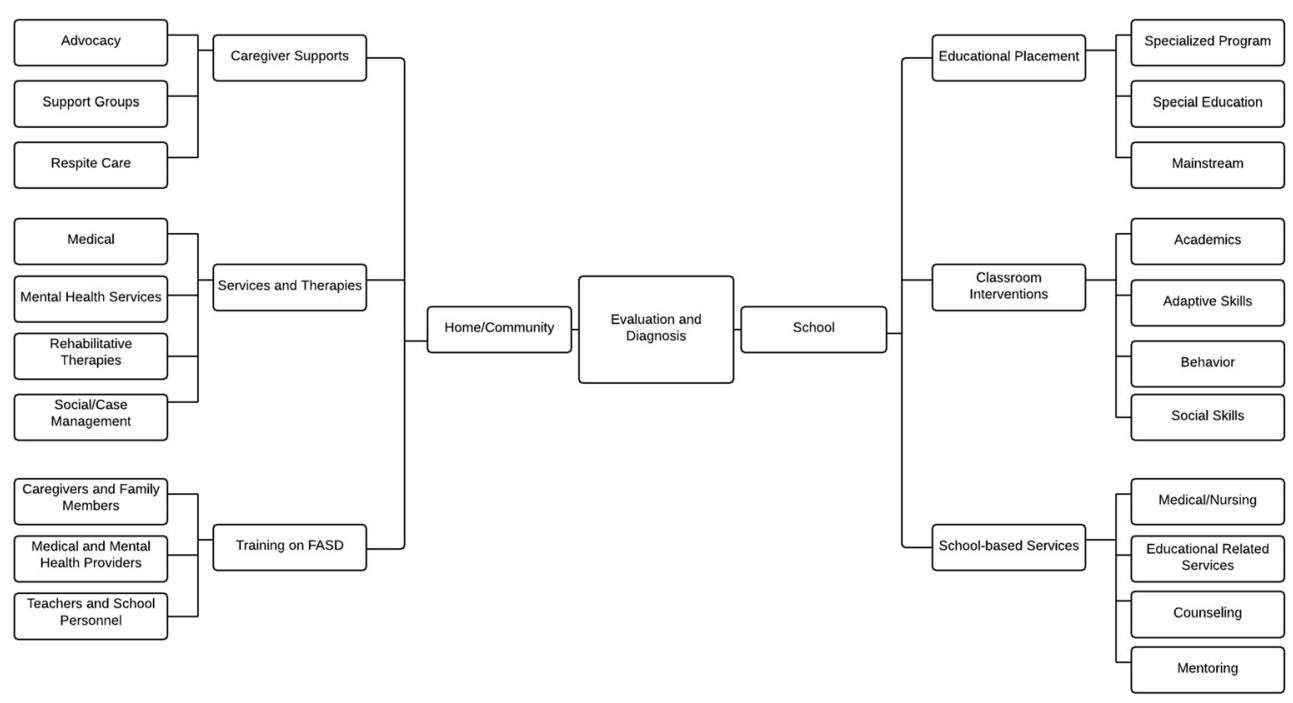

Fig. 1 a Educational planning for children affected by PAE begins with a comprehensive evaluation to determine an accurate diagnosis, level of functioning, and recommendations for interventions. b The results from the evaluation, information about school performance, and input from teachers and caregivers are needed to select the appropriate school program, classroom placement, and instructional supports. c This includes determining the types of educational related services such as occupational therapy, physical therapy, speech and language therapy,

opportunities for frequent review of the information. It is important for teachers to assess the demands of each classroom task to determine if they are on an appropriate level [62-64]. Tasks that are too difficult or too easy may influence children's behaviors. Modification of instruction needs to be developed according to the children's learning profile. Some children require changes in formats of grade level materials to lessen interference from irrelevant information while others require direct instruction using curriculum at a lower level [61, 62].

Some alcohol-affected children display behavior problems due to cognitive impairments, neglectful environments, or other factors and despite modifications to instruction and curriculum. In such cases, a comprehensive functional behavior analysis should be completed by a trained psychologist or behavioral specialist to investigate the purpose and events related to behaviors. Upon completion of the behavioral analysis, a positive behavior intervention plan would need to be developed. The behavior plan needs to outline specific strategies to teach children affected by PAE the skills to respond and interact effectively across school settings [65].

\section{Individualized Academic Interventions}

Interventions have been developed to address deficits in learning readiness, mathematics, social interactions, behavior, attention, and executive processes associated with the effect of PAE [66-74]. However, there has been little-to-no research examining academic challenges and interventions for children with PAE to address deficits in reading, written expression, or counseling, and social skills training. d Caregivers require information on how to advocate for services, communicate effectively with schools and teachers, as well as receive supports. $\mathbf{d}$ Teachers require information on the effects from PAE on learning and strategies to address concerns that are relevant to a classroom setting. e Collaboration between caregivers, medical and mental health providers, and teachers is required to ensure the effectiveness of the educational program

content areas such as science or social studies [66, 67, 75]. Interventions to address these areas need to be selected from effective programs used to remediate other learning disorders $[60,61]$. Effective intervention programs designed for children with PAE share common elements [52]. Effective intervention programs address underlying cognitive deficits within the context of an everyday skill or learning task. Instruction is presented on the children's developmental and ability levels. The interventions focus on changing thinking patterns rather than increasing rote skills [52, 63, 67]. Also, caregivers are provided activities to reinforce the skills at home.

These characteristics may be applied to develop individualized academic interventions for alcohol-affected children to be used at school. For example, many children affected by PAE exhibit problems with executive functioning that interfere with planning and use of efficient problem-solving strategies $[1,3,56,70]$. To address these weaknesses, teachers may use mediated learning strategies to direct children to use selftalk in order to analyze information and work through problems systematically. The math interactive learning experience (MILE), a learning readiness and mathematics program designed for children affected by PAE, uses a technique called FAR, which refers to focus/plan, act, and reflect, to improve children's problems solving efficiency [76]. During the focus/ plan stage, children are taught to attend to the important elements of a problem. The act stage requires children to verbalize the steps they use to solve problems as they complete the task. The reflect stage requires children to share what they learned and discuss what strategies were effective to solve the 
problems. The interactions between teachers and children provide opportunities for frequent review in order to encode information. Also, the interactions help children engage and sustain mental effort to complete tasks [52, 76-78]. This approach has been found to improve children's problem-solving efficiency, learning readiness, and behavior [52, 76, 77]. The use of FAR or a similar approach may be incorporated into learning tasks across academic subjects $[75,76]$. Additionally, caregivers may be taught to use the FAR technique with their children at home while completing homework or household chores.

Interventions have been developed to address deficits in mathematics associated with the effects from PAE. The interventions for mathematics target deficits in visuospatial processing, working memory, and executive functioning and provide instruction to understand basic numerical and mathematical concepts [76]. Despite the age of the learner, mathematics instruction needs to use carefully selected manipulatives, or small items such as blocks, to provide a concrete representation of the skill or concept. This is to link language with the visual information to create a mental representation of a mathematical concept or skill. These objects need to be simple and without intricate visual details to prevent interference with learning [79]. Using mediated learning strategies such as the FAR method, instructors can guide children to apply their understanding of a mathematical concept or skill to solve problems efficiently using manipulatives $[76,78,79]$. Once children are able to demonstrate accurate application of the taught concept or skill using manipulatives, teachers need to provide direct instruction to transform the information into mathematical symbols. The focus of the interventions is to change ineffective thinking patterns and to teach children to use the skills independently [52, 63, 69]. Children who received interventions during clinical studies using this approach showed gains in their mathematic skills [76-78].

\section{Educational Related Services}

Some children affected by PAE require educational supportive services such as speech and language therapy, occupational therapy, physical therapy, and social skills training. These services may be obtained at school as well as through private providers. Additionally, many children affected by PAE may require mentoring and afterschool support to complete homework and facilitate school functioning. Educational plans need to consider how to obtain these supports at school or through community programs $[60,68]$.

\section{Training for Educators}

Teachers and school staff would benefit from training on the effects from PAE. The training needs to provide an overview of the impact of PAE on cognition, behavior, and learning. Workshops and trainings for teachers need to provide information on evidence-based interventions and how to apply the strategies in a school or classroom setting. Teachers, school counselors, psychologists, and administrators would benefit from training on maintaining the confidentiality of sensitive health information and on ways to discuss the issues associated with PAE with biological mothers and caregivers without reinforcing the feelings of shame or isolation. It is important to build trust between the caregivers and school personnel in order to work collaboratively $[16,18 \bullet]$.

\section{Caregivers}

Caregiver involvement has been shown to have a positive effect on educational outcomes. The caregivers of children affected by PAE would benefit from training to help them understand the effects of PAE on development and learning. This includes guidance on how to understand their children's cognitive and learning profile in relation to the disorder in order to provide support at home [52, 68, 69, 76, 77]. Also, caregivers need guidance on how to talk with their children regarding their learning challenges on an appropriate developmental level. This is to begin the process to teach children the skills to learn to advocate for their own needs as they progress into adulthood [69, 76, 77].

Caregivers need information on how to advocate for school services. This includes providing information and resources regarding the rules and regulations for their school system or district [61]. The purpose is to help caregivers understand the types of programs and services school systems are required to provide. Understanding the procedures as well as the limitations of school services may lessen the possibility of unnecessary conflicts when negotiating to obtain school-based services. Additionally, caregivers may require training on how to establish efficient communication with teachers and other school professionals $[57,60]$. This is to assist with monitoring progress and to identify concerns before they become problematic.

\section{Conclusion}

Educational planning and care for children affected by PAE require collaborative efforts among caregivers, educators, and other professionals to develop effective programs. It is important for caregivers, educators, and other professionals to understand the impact of PAE and environmental factors on neurodevelopment, behavior, and learning in order to obtain the appropriate level of services. Children with global developmental delays as a result of PAE may require intensive specialized instruction and therapies provided on an individual basis and or in a small group setting [52, 63, 68, 69]. However, children, who display fewer effects from PAE, may require supports from special educators, tutors, and mentors while receiving instruction in a general education setting. 
Studies examining interventions to address deficits in mathematics, learning readiness, self-regulation, parent-child interactions, and behavior in children affected by PAE have had positive results [68-76]. Based upon these studies, individualized academic and school-based interventions for children with PAE need to address the underlying cognitive deficiencies within the context of a learning skill, use materials and instructional methods that are developmentally appropriate, and incorporate caregiver involvement $[52,76]$. Caregivers require training and support on how to advocate for their children's services in schools [16, 18•]. Training for school personnel needs to provide an overview of the impact of PAE on development and learning. The training needs to provide specific strategies to address issues associated with PAE in the classroom setting. Also, training needs to include ways for teachers and other school professionals to discuss the sensitive issues associated with PAE with biological mothers and caregivers to facilitate trust and collaboration in order to promote a welcoming educational environment [18•, 57].

The focus of educational intervention is to habilitate skills so that children with PAE can be active and successful learners. However, more research is needed to explore the impact of PAE on learning, academic achievement, and school functioning. Specifically, research is needed to examine academic skills in the areas of written expression, reading comprehension, and content areas such as science and social studies. Also, research is needed to examine ways to help older students transition from high school to postsecondary school training and or vocational programs. Providing the appropriate educational care for children affected by PAE is necessary to prevent school failure and subsequent problems that could have negative long-term consequences.

\section{Compliance with Ethics Guidelines}

Conflict of Interest The author declares that she has no competing interests.

Human and Animal Rights Informed Consent This article does not contain any studies with human or animal subjects performed by the author.

\section{References}

Papers of particular interest, published recently, have been highlighted as:

- Of importance

•. Of major importance

1. Mattson SN, Crocker N, Nguyen TT. Fetal alcohol spectrum disorders: neuropsychological and behavioral features. Neuropsychol Rev. 2011;21(2):81-101. doi:10.1007/s11065-011-9167-9.
2.• Flak AL, Su S, Bertrand J, et al. The association of mild, moderate, and binge prenatal alcohol exposure and child neuropsychological outcomes: a meta-analysis. Alcohol Clin Exp Rev. 2014;38(1):21426. doi:10.1111/acer.12214. An overview of the range of cognitive impairments associated with maternal alcohol use during pregnancy. The study shows that low to moderate alcohol use is associated with fewer effects than long-term and binge drinking.

3. Davis K, Desrocher M, Moore T. Fetal alcohol spectrum disorders: a review of neurodevelopmental findings and interventions. J Dev Phys Disabil. 2011;23:143-67. doi:10.1007/s10882-010-9204-2.

4. Mattson SN, Roesch SC, Glass L, et al. Further development of a neurobehavioral profile of fetal alcohol spectrum disorders. Alcohol Clin Exp Res. 2013;37(3):517-28. doi:10.1111/j.15300277.2012.01952.x.

5. Coles CD. Discriminating the effects of prenatal alcohol exposure from other disorders. Alcohol Res Health. 2011;34(1):42-50.

6. Streissguth AG, Barr HM, Kogan J, et al. Understanding the occurrence of secondary disabilities in clients with fetal alcohol syndrome (FAS) and fetal alcohol effects (FAE): final report to the centers for disease control on grant no R04/CCR008515 (Tech. Report No 96-16). Seattle: University of Washington, Fetal Alcohol and Drug Unit; 1996.

7. Streissguth AP, Bookstein FL, Barr HM, et al. Risk factors for adverse life outcomes in fetal alcohol syndrome and fetal alcohol effects. J Dev Behav Pediatr. 2004;25(4):228-38.

8. Hussong A, Huamg W, Curran P. Parent alcoholism impacts the severity and timing of children's externalizing symptoms. J Abnorm Child Psychol. 2010;38:367-80.

9. Koponen AM, Kalland M, Rämö-Autti I. Caregiving environment and socio-emotional development of foster-placed FASD children. Child Youth Serv Rev. 2009;31:1049-56. doi:10.1016/j. childyouth.2009.05.006.

10. Streissguth AP, Barr HM, Olsen HC, et al. Drinking during pregnancy decreases word attack and arithmetic scores on standardized tests: adolescent data from a population-based prospective study. Alcohol Clin Exp Res. 1994;19(2):248-54.

11. Streissguth AP, Sampson PD, Olsen HC, et al. Maternal drinking during pregnancy: attention and short-term memory in 14-year-old offspring - a longitudinal prospective study. Alcohol Clin Exp Res. 1994;18(1):202-18.

12. Goldschmidt L, Richardson GA, Stoffer DS, et al. Prenatal alcohol exposure and academic achievement at age six: a nonlinear fit. Alcohol Clin Exp Res. 1996;20(4):763-70.

13. Goldschmidt L, Richardson GA, Cornelius MD, et al. Prenatal marijuana and alcohol exposure and academic achievement at age 10. Neurotoxicol Teratol. 2004;26:521-32. doi:10.1016/j.ntt.2004.04. 003.

14. O'Leary CM, Taylor C, Zubrick SR, et al. Prenatal alcohol exposure and educational achievement in children aged 8-9 years. Pediatrics. 2013;132:e468-75. doi:10.1542/peds.2012-3002.

15. Rangmar J, Hjern A, Vinnerijung B, et al. Psychosocial outcomes of fetal alcohol syndrome in adulthood. Pediatrics. 2015;135:e52-8. doi: $10.1542 /$ peds2014-1915. The article provides a review of the educational, economic, employment, and social outcomes of adults affected PAE who were diagnosed as children.

16. Swart S, Hall WA, McKee WT, et al. Caregivers' management of schooling for their children with fetal alcohol spectrum disorder. Qual Health Res. 2014;24(11):1540-52. doi:10.1177/ 1049732314545497.

17. Ryan S, Ferguson D. On, yet under, the radar: students with fetal alcohol syndrome disorder. Except Child. 2006;72(3):363-79.

18. Petreko CLM, Tahir N, Mahoney EC, et al. Prevention of secondary conditions in fetal alcohol spectrum disorders: identification of systems-level barriers. Matern Child Health J. 2014;18:1496-505. doi:10.1007/s10995-013-1390-y. The article presents an 
overview of the difficulties caregivers experience when attempting to obtain service for children with PAE.

19. Dybdahl CS, Ryan S. Inclusion for students with fetal alcohol syndrome: classroom teachers talk about practice. Prev Sch Fail. 2009;55(3):185-95.

20. Duquette C, Stodel E, Fullarton S, et al. Persistence in high school: experiences of adolescents and young adults with fetal alcohol spectrum disorder. J Intellect Dev Disabil. 2006;31(4):210-31. doi:10.1080/13668250601031930.

21. Pei J, Job JM, Poth C, et al. Assessment for intervention of children with fetal alcohol spectrum disorders: perspectives of classroom teachers, administrators, caregivers, and allied professionals. Psychology. 2013;4(3A):325-34. doi:10.4236/psych.2013. 43A047.

22. Pelco LE, Ward SB, Coleman L, et al. Teacher ratings of three psychological report styles. Train Educ Prof Psychol. 2009;3(10): 19-27. doi:10.1037/1931-3918.3.1.19.

23. Chasnoff IJ, Wells AM, King L. Misdiagnosis and missed diagnoses in foster and adopted children with prenatal alcohol exposure. Pediatrics. 2015;135(20):262-70. doi:10.1542/peds.2014-2171.

24. Thompson-St. Clair HL, Gathercole SE. Executive functions and achievements in school: shifting, updating, inhibition, and working memory. Q J Exp Psychol. 2006;59(4):745-59. doi:10.1080/ 17470210500162854

25.• Crocker N, Riley EP, Mattson SN. Visual-spatial abilities relate to mathematics achievement in children with heavy prenatal alcohol exposure. Neuropsychology. 2015;29(1):108-16. doi:10.1037/ neu0000094. The article discusses the impact of visuo-spatial deficits on arithmetic and discusses avenues for further research to investigate mathematical deficits associated with the effects from PAE.

26. Howell KK, Lynch ME, Platzman KA, et al. Prenatal alcohol exposure and ability, academic achievement, and school functioning in adolescence: a longitudinal follow-up. J Pediatr Psychol. 2006;31(1):116-26. doi:10.1093/jpepsy/jsj029.

27. Coles CD, Brown RT, Smith IE, et al. Effects of prenatal alcohol exposure at school age. I. Physical and cognitive development. Neurotoxicol Teratol. 1991;13:357-67.

28. Kopera-Frye K, Dehaene S, Streissguth S. Impairments of number processing induced by prenatal alcohol exposures. Neuropsychologica. 1996;34(12):1187-96.

29. Meintijes EM, Jaobson JL, Molteno CD, et al. An fMRI study of number processing in children with fetal alcohol syndrome. Alcohol Clin Exp Res. 2010;34(8):1450-60. doi:10.1111/j.15300277.2010.01230.x.

30. Jacobson J, Dodge NC, Burden MJ, et al. Number processing in adolescents with prenatal alcohol exposure and ADHD: differences in the neurobehavioral phenotype. Alcohol Clin Exp Res. 2011;35(3):431-42. doi:10.1111/j.1530-0277.2010.01360.x.

31. Santhanam P, Li Z, Hu X, et al. Effects of prenatal alcohol exposure on brain activation during an arithmetic task: an fMRI study. Alcohol Clin Exp Res. 2009;33(11):1901-8. doi:10.1111/j.15300277.2009.01028.x.

32. Le Fevre J-A, Berrigan L, Vendetti C, et al. The role of executive attention in the acquisition of mathematical skills for children in Grades 2 through 4. J Exp Psychol Gen. 2013;114:243-61. doi: 10.1016/j/jecp.2012.10.005.

33. Crocker N, Vaurio L, Riley EP, et al. Comparison of verbal learning and memory in children with heavy prenatal alcohol exposure or attention-deficit hyperactivity disorder. Alcohol Clin Exp Res. 2011;35(6):1114-21. doi:10.1111/j.1530-0277.2011.01444.x.

34. Coles CD, Lynch ME, Kable JA, et al. Verbal and nonverbal memory in adults prenatally exposed to alcohol. Alcohol Clin Exp Res. 2010;34(5):897-906. doi:10.1111/j.1530-0277.2010.01162.x.
35. Kully-Martins K, Pei J, Job J, et al. Source monitoring in children with and without fetal alcohol spectrum disorders. J Pediatr Psychol. 2012;37(3):725-35. doi:10.1093/jpepsy/jsr123.

36. Roebuck-Spencer TM, Mattson S. Implicit strategy affects learning in children with heavy prenatal alcohol exposure. Alcohol Clin Exp Res. 2004;28(9):1424-31. doi:10.1097/01.ALC.0000139826. 25247.5B

37. Rasmussen C, Pei J, Manji S, et al. Memory strategy development in children with foetal alcohol spectrum disorders. Dev Neurorehabil. 2009;12(4):207-14. doi:10.1080/ 17518420902980126

38. Coggins TE, Friet T, Morgan T. Analysing narrative production in older school-age children and adolescents with fetal alcohol syndrome: an experimental tool for clinical applications. Clin Linguist Phon. 1998;12(3):221-36.

39. Coggins TE, Timler GR, Olswang LB. A state of double jeopardy: impact of prenatal alcohol exposure and adverse environments on the social communication abilities of school-age children with fetal alcohol spectrum disorder. Lang Spech Hear Serv Sch. 2007;38: $117-27$

40. Olswang LB, Svensson L, Astley A. Observation of classroom communication: do children with fetal alcohol spectrum disorders spend their time differently than their typically developing peers? J Speech Lang Hear Res. 2010;53:1687-703.

41. McGee CL, Fryer SL, Bjorkquist OA, et al. Deficits in social problem solving in adolescents with prenatal alcohol exposure. Am J Drug Alcohol Abuse. 2008;34:423-31. doi:10.1080/ 00952990802122630

42.• Stevens SA, Dudek J, Nash K, et al. Social perspective taking and empathy in children with fetal alcohol spectrum disorders. J Int Neuropsychol Soc. 2015;21:74-84. doi:10.1017/ S1355617714001077. The study examines social cognition and empathy in older and younger children affected by PAE as compared to typical developing peers. Children affected by PAE showed poorer performance on measures tests assessing social cognition.

43. Kjellmer L, Olswang L. Variability in classroom social communication: performance of children with fetal alcohol spectrum disorders and typically developing peers. J Speech Lang Hear Res. 2013;56:982-93. doi:10.1044/1092-4388(2012/11-0345).

44. Streissguth AP. Offspring effects of prenatal alcohol exposure from birth to 25 years: the Seattle prospective longitudinal study. J Clin Psychol Med Settings. 2007;14:81-101. doi:10.1007/s10880-0079067-6.

45. Lynch ME, Coles CD, Corley T, et al. Examining delinquency in adolescents differentially prenatally exposed to alcohol: the role of proximal and distal risk factors. J Stud Alcohol. 2003;64:678-86.

46. Kelly YJ, Sacker A, Gray R, et al. Light drinking during pregnancy: still no increased risk for socioemotional difficulties or cognitive deficits at 5 years of age. J Epidemiol Community Health. 2010;66: 41-8.

47. Wozniak JR, Mueller BA, Bell CJ, et al. Global functional connectivity abnormalities in children with fetal alcohol spectrum disorders. Alcohol Clin Exp Res. 2013;27(5):748-56. doi:10.1111/acer. 12024.

48. Fryer SC, Mattson SN, Jerigan TL. Caudate volume predicts neurocognitive performance in youth with heavy prenatal alcohol exposure. Alcohol Clin Exp Res. 2012;36(11):1932-41. doi:10. 1111/j.1530-0277.2012.01811.

49. Ware AL, Crocker N, O'Brien JW, et al. Executive function predicts adaptive behavior in children with histories of prenatal alcohol exposure and attention-deficit/hyperactivity disorder. Alcohol Clin Exp Res. 2012;36(8):1431-41. doi:10.1111/j.1530-0277.2011. 01718.x. 
50. Hofman W, Schmeichel BJ, Baddeley AD. Executive functions and self-regulation. Trends Cogn Sci. 2012;16(3):174-80. doi:10.1016/ j.tics.2012.01.006.

51. Hofer M. Goal conflicts and self-regulation: a new look at pupil offtask behavior in the classroom. Educ Res. 2007;2:28-38. doi:10. 1016/j.edurev.2007.02.002.

52. Bertrand J. Interventions for children with fetal alcohol spectrum disorders (FASDs): overview of the findings for five innovative research projects. Res Dev Disabil. 2009;30:986-1006. doi:10. 1016/j.ridd.2009.02.003.

53. Burden MJ, Jacobson JL, Westerlund A, et al. An event-related potential study of response inhibition in ADHD with and without prenatal alcohol exposure. Alcohol Clin Exp Res. 2010;34(4):61727. doi:10.1111/j.1530-0277.2009.01130.x.

54. Ware AL, O'Brien JW, Crocker N, et al. The effects of prenatal alcohol exposure on attention-deficit/hyperactivity disorder on psychopathology and behavior. Alcohol Clin Exp Res. 2013;37(3): 507-16. doi:10.1111/j.1530-0277.2012.01953.x.

55. Glass L, Ware AL, Crocker N, et al. Neuropsychological deficits associated with prenatal alcohol exposure are not exacerbated by ADHD. Neuropsychology. 2013;27(6):713-24. doi:10.1037/ a0033994.

56. Koostra L, Crawford S, Gibbard B, et al. Differentiating attention deficits in children with fetal alcohol spectrum disorder or attentiondeficit-hyperactivity disorder. Dev Med Child Neurol. 2010;52: 205-11. doi:10.1111/j.1469-8749.2009.03352.

57. Millar JA, Thompson J, Schwab D, et al. Educating students with FASD: linking policy, research, and practice. JORSEN. 2014. doi: 10.1111/1471-3802.12090.

58. Racine E, Bell E, Di Pietro NC, et al. Evidence-based neuroethics for neurodevelopmental disorders. Sem Pediatr Neurol. 2011;18(1): 21-5. doi:10.1016/j.spen.2011. 02.002.

59. Riggie JL, Xu T. Supporting individuals with fetal alcohol spectrum disorders: a summary of effective practices. Phys Disabil Educ Relat Serv. 2013;32(2):43-89. doi:10.14434/pders.v32i2.12996.

60. Green J. Fetal alcohol spectrum disorders: understanding the effects of prenatal alcohol exposure and supporting students. J Sch Health. 2007;77(3):103-8.

61. Fuchs D, Deshler D. What we need to know about responsiveness to intervention (and shouldn't be afraid to ask). Learn Disabil Res Pract. 2007;22(2):129-36.

62. O'Connor RE, Klinger J. Poor responders in RTI. Theory Pract. 2010;49:297-304. doi:10.1080/00405841.2010.510758.

63. Kodituwakku PW. A neurodevelopmental framework for the development of interventions for children with fetal alcohol spectrum disorders. Alcohol. 2010;44:717-28. doi:10.1016/j.alcohol.2009. 10.009 .

64. Zentall SS. Theory and evidence-based strategies for children with attentional problems. Psychol Sch. 2005;42(8):821-36. doi:10. 1002/pits.20114.

65. Gann CJ, Ferro JB, Umbreit J, et al. Effects of a comprehensive function-base intervention applied across multiple educational settings. Remedial Spec Educ. 2014;35(1):50-60. doi:10.1177/ 0741932513501088.

66. Peadon E, Rhys-Jones B, Bower C, et al. Systematic review of interventions for children with fetal alcohol spectrum disorders. BMC Pediatr. 2009;9(35):1-9. doi:10.1186/1471-2431-9-35.

67. Premji S, Benzies K, Serrett K, et al. Research-based interventions for children and youth with a fetal alcohol spectrum disorder: revealing the gap. Child Care Health Dev. 2006;33(4):389-97. doi: 10.1111/j.1365-2214.2006.00692.x.

68. Kalberg WO, Buckley D. FASD: what types of intervention and rehabilitation are useful? Neurosci Biobehav Rev. 2007;31:278-85. doi:10.1016/j.neubiorev.2006.06.014.

69. Kodituwakku PK, Kodituwakku EL. From research to practice: an integrative framework for the development of interventions for children with fetal alcohol spectrum disorders. Neuropsychol Rev. 2011;24:204-23. doi:10.1007/s11065-011-9170-1.

70. Paley B, O'Connor MJ. Behavioral interventions for children and adolescents with fetal alcohol spectrum disorders. Alcohol Res Health. 2011;34(1):64-75.

71. Kerns KA, MacSween J, Vander Wekken S, et al. Investigating the efficacy of an attention training programme in children with foetal spectrum disorder. Dev Neurorehabil. 2010;13(6):413-22. doi:10. 3109/17518423.2010.511421.

72. Wells AM, Chasnoff IJ, Schmidt CA, et al. Neurocognitive habilitation therapy for children with fetal alcohol spectrum disorders: an adaptive of the alert program ${ }^{\circledR}$. Am J Occup Ther. 2012;66(1):24 36. doi:10.5014/ajot.111.002691.

73. O'Connor MJ, Frankel F, Paley B, et al. A controlled social skills training for children with fetal alcohol spectrum disorders. J Consult Clin Psychol. 2006;74(4):639-48. doi:10.1037/0022-006X.74.4. 639.

74. O'Connor MJ, Laugenson EA, Mogil C, et al. Translation of an evidence-based social skills intervention for children with prenatal alcohol exposure in a community mental health setting. Alcohol Clin Exp Res. 2012;36(1):141-52. doi:10.1111/j.1530-0277.2011. 01591.x.

75. Adnams CM, Sorour P, Kalberg WO, et al. Language and literacy outcomes from a pilot intervention study for children with fetal alcohol spectrum disorders in South Africa. Alcohol. 2007;41: 403-14. doi:10.1016/j.alcohol.2007.07.005.

76. Kable JA, Coles CD, Taddeo E. Socio-cognitive habilitation using the math interactive learning experience (MILE) program for alcohol-affected children. Alcohol Clin Exp Res. 2007;31(8): 1425-34.

77. Coles CD, Kable JA, Taddeo E. Math performance and behavior problems in children affected by prenatal alcohol exposure: intervention and follow-up. J Dev Behav Pediatr. 2009;30:7-31.

78. Kable JA, Taddeo E, Strickland D, et al. Community translation of the math interactive learning experience program for children with FASD. Res Dev Disabil. 2015;39:1-11. doi:10.1016/jridd.2014.12. 031.

79. McNeil N, Jarvin L. When theories don't add up: disentangling the manipulatives debate. Theory Pract. 2007;46(4):309-16. 